\title{
BMJ Global Health Neglected tropical diseases as a barometer for progress in health systems in times of COVID-19
}

Nieves Ehrenberg (D , ${ }^{1}$ John P Ehrenberg, ${ }^{2}$ Gilberto Fontes, ${ }^{3}$ Margaret Gyapong, ${ }^{4}$ Eliana M M Rocha, ${ }^{3}$ Peter Steinmann, ${ }^{5,6}$ Jürg Utzinger, ${ }^{5,6}$ Xiao-Nong Zhou, ${ }^{7,8}$ Don de Savigny ${ }^{5,6}$
To cite: Ehrenberg N,

Ehrenberg JP, Fontes G, et al. Neglected tropical diseases as a barometer for progress in health systems in times of COVID-19. BMJ Global Health 2021;6:e004709. doi:10.1136/ bmjgh-2020-004709

Handling editor Seye Abimbola

Received 9 December 2020 Revised 18 February 2021 Accepted 21 February 2021
Check for updates

(c) Author(s) (or their employer(s)) 2021. Re-use permitted under CC BY-NC. No commercial re-use. See rights and permissions. Published by BMJ.

For numbered affiliations see end of article.

\section{Correspondence to} Ms Nieves Ehrenberg; nieves.ehrenberg@outlook. com and

Professor Don de Savigny; d.desavigny@swisstph.ch

\section{INTRODUCTION}

The year 2020 will be regarded as the year when the SARS-CoV-2 resulted in the COVID-19 pandemic that spread globally, catching most countries unprepared. Amid untold suffering, COVID-19 presents the opportunity to galvanise support for long due social, political and economic reforms to address the root causes of ill-health and inequities, but also to radically transform health and social protection systems to enable more effective performance and resilience to systemic shocks. ${ }^{1}$

Like neglected tropical diseases (NTDs), the COVID-19 pandemic has a poverty-related dimension, hitting hardest at marginalised populations. ${ }^{2}$ This paper argues that NTDs offer valuable insights for building back better health systems for pandemic preparedness, while also providing an important barometer for progress in health and social protection.

\section{FAULT LINES IN HEALTH AND CARE SYSTEMS}

The COVID-19 pandemic has exposed serious failures in health and care systems in high-income, middle-income and low-income countries alike. Fragmentation and a lack of intersectoral responses have prevented countries from responding effectively. For example, information and data collection systems are usually not integrated, comprehensive or rapid enough to provide a full picture of the pandemic's impact to readily inform decision-makers, even for such basic indicators as mortality. The failure to implement community-based surveillance and response has made it difficult to manage the spread of SARS-CoV-2. Moreover, public health communication has been weak in most places, confusing and misleading in others.

Part of the problem is that decision-makers are often beholden to political and economic

\section{Summary box}

Despite huge challenges, the COVID-19 pandemic presents unique opportunities for systems change.

- Current recovery plans are lacking systems change that are fit for the future.

- Efforts to build back better need to combine climate, economic, health and socio-political systems into an integrated approach.

- Neglected tropical diseases offer valuable insights for addressing the gaps and will be an important barometer for progress in responding to the needs of the most disadvantaged populations and for building back better.

interests that go against sustainable and equitable solutions. A major design flaw in policy-making is the lack of a systems view to tackle new challenges by understanding the complex interactions of different parts of the system, their causes and effects. ${ }^{3}$ For example, frequently, the epidemiological projections of the effects of a disease outbreak do not take into account economics and how people will respond to emerging health risks. Conversely, economists lack an understanding of how an outbreak affects economic forecasts. As a result, it is difficult for countries, regions or indeed, the international community to act as 'one system' as required in complex situations and major crises.

There is no doubt that the human and economic consequences of the COVID-19 pandemic are particularly profound for the most vulnerable citizens and communities. The Institute for Health Metrics and Evaluation estimated that extreme poverty has already increased by $7 \%$ because of COVID19 , ending a 20-year streak of progress in just a few months. ${ }^{4}$ The COVID-19 pandemic, with its disproportionate impact on those who have been historically marginalised and 
Box 1 Brazil's Unified Health System-the gap between theory and practice

- Brazil's Unified Health System (Sistema Único de Saúde (SUS)) was created in 1988, making Brazil one of the largest countries in the world to have a public health system that provides free care to every citizen, including the most vulnerable. Today, 162 million people depend exclusively on SUS. ${ }^{38}$ Were it not for this system, more than 13 million unemployed and 38 million informal Brazilian workers would not have access to healthcare. ${ }^{39}$ In reality, the healthcare workforce is unevenly distributed across the country, with few if any in some areas, particularly rural and remote areas. ${ }^{40}$ Mismanagement of public funds at the federal, state and municipal levels is one of several inefficiencies, and one of the main problems faced by the country's public healthcare system ${ }^{40}$ that has led to a decay in the SUS. In principle, SUS is a comprehensive and inclusive system. In practice, however, COVID-19 revealed the magnitude of the gap between theory and practice.

neglected (including racially minoritised people ${ }^{5}$ indigenous populations, women, migrants and those living in poverty) exposed the inadequacy of most societies' policies for tackling existing systemic inequities-inequities that are in turn being greatly exacerbated by the pandemic.

The failure to implement effective Universal Health Coverage (UHC) has left many without access to the routine health services they need. This points towards systemic and systematic inequities that are endemic in the world's political, economic and health systems. The ongoing erosion of confidence in science further compounds these challenges. Box 1 describes the gap between the theory of UHC and achieving it in practice.

Following the epidemics due to SARS in China (20022003), Ebola in West Africa (2013-2016) and Zika in Brazil (2015-2016), there was a wealth of studies and reports on how to strengthen health systems and make them more resilient to cope with such crises. ${ }^{67}$ Decisionmakers in most countries mistakenly perceived other issues as having higher priorities and failed to take action.

Several countries are now for the first time considering or even planning major social, political and economic reforms. Important financial opportunities are on the horizon to reactivate economies hit by COVID-19. ${ }^{8}$ This pandemic could thus prove to be the catalyst to transform the global, national and local health and care systems.

\section{INSIGHTS FROM NTD CONTROL PROGRAMMES}

NTDs are a diverse group of diseases, caused by an array of aetiological agents such as bacteria, fungi, parasites and viruses. The official list of NTDs, according to the WHO, currently includes 20 conditions. ${ }^{9}$ Though officially not acknowledged as NTDs by WHO, there are over 20 others that are bracketed as NTDs by those in this field, including various mycoses and diseases caused by protozoal species. ${ }^{10}$ One in five people worldwide is at risk of NTDs, which generally affect the poorest 1.6 billion people living in the most marginalised communities. ${ }^{11}$ NTDs result in substantial disability, stigma and loss of livelihood, in addition to the deaths caused. Given these diseases are by definition neglected, there are considerable uncertainties regarding global burden estimates. ${ }^{10}$ NTDs are considered an indicator of poverty, as poverty is a strong risk factor for acquiring many NTDs. Furthermore, NTDs entail not only considerable health and care costs but also adversely impact the poorest people's economic activities. ${ }^{12}$

With some exceptions, NTD control tends to be weakly integrated into health systems, a fact which continuously challenges the sustainability of NTD control programmes. Hardly any NTD is subject to compulsory reporting, and hence most fall outside the radar of the authorities. This might explain why few, if any, are considered a public health priority by endemic countries. Fortunately, and thanks to the initiative of private foundations, philanthropic organisations and pharmaceutical companies, successful alliances and public-private partnerships, such as the Global Programme to Eliminate Lymphatic Filariasis, have been established over the past two decades, encouraging more active involvement of the public sector and resulting in a host of successful NTD control and elimination efforts. Despite NTD determinants lying well beyond the purview of the health sector alone, they continue to rely for the most part on diseasespecific vertical approaches with only minor intersectoral involvement. ${ }^{13}$

Critical failings in global NTD control efforts have been identified. ${ }^{14}$ They include disease burdens not estimated or updated, failure to recognise the importance of the climate emergency, poverty and inequality even in wealthy nations, and insufficient research and development investments. Box 2 describes a successful NTD control programme and how, despite its success, health systems' capacity remains a challenge.

The new road map for NTDs for the period 2021$2030^{15}$ was intended to be officially launched in June 2020 but was postponed to January 2021 due to the COVID-19 pandemic. It highlights the need for: (i) greater integration across NTDs, such as having a common delivery platform combining efforts across multiple diseases; (ii) mainstreaming within national health systems, improving the quality of NTD management in the context of UHC; (iii) coordinating efforts among a range of stakeholders working with other sectors within and beyond health on NTD-relevant interventions; and (iv) addressing health systems and primary healthcare infrastructure.

Mass Drug Administration and other community-based services have been suspended in most countries as a result of COVID-19 and there have been delays in diagnosis, treatment, morbidity management, disability prevention and a host of other services. ${ }^{16}$ Although WHO has been proactive in providing guidance for resuming NTD activities, ${ }^{17}$ the impact of this disruption will be felt for years to come. 
Box 2 Neglected tropical disease (NTD) control and elimination depends on multisectoral collaboration and strong health systems

- Perhaps no other NTD programme illustrates better the challenges behind a successful control or elimination effort as the Global Programme to Eliminate Lymphatic Filariasis. Although impressive progress has been achieved, a recent paper pointed out that there are considerable challenges with the implementation of the central strategy - that is, periodic mass drug administration (MDA). ${ }^{41}$ It is to be expected that COVID-19 will only exacerbate this situation, particularly in countries with the weakest health systems. Despite being administered as a single annual round for lymphatic filariasis, MDA requires the engagement of all components of the health system, including service delivery, governance, financing, supply chains, human resources and information technologies. Among the greatest challenges faced by NTD control programmes is the capacity of health systems to deliver interventions at the community level and in rural areas where access to routine healthcare is lacking. This is one reason why many programmes rely on partnerships with the educational and other sectors. Access to healthcare in marginalised population groups is also a major issue in COVID-19. Multisectoral collaboration and integrated health and care systems are needed to tackle both NTDs and COVID-19.

\section{GAPS IN CURRENT COVID-19 RECOVERY PLANS}

Most countries are preparing COVID-19 recovery plans. Some of the countries that have been worst affected, including Brazil ${ }^{18}$ Mexico, ${ }^{19}$ the $\mathrm{USA}^{20}$ and the UK, ${ }^{21}$ are countries that over the recent past have turned the clock back on tackling inequities and the root causes of ill-health in a quest for efficiency. In these, and several other countries, current plans are still reacting to events as they unfold, hence the focus remains on containment and mitigation relying on clinical and laboratorycentric efforts and supply chains. Moving forward, space needs to be devoted to increasing the focus on primary, community, social and mental healthcare, which creates the opportunity to transform economies and societies to become fairer, more responsive and resilient.

New Zealand is hailed as one of the countries that have so far managed the pandemic successfully. Geography (New Zealand is an island) has certainly played a part in this, but importantly, considerable efforts were made there over the past decade to strengthen primary care and to better integrate health and social services. The infrastructure, trust and relationships built through this work meant the system was better prepared to respond to the pandemic. Yet, existing inequities still need to be addressed. A recent study found that the risk of dying from COVID-19 is at least 50\% higher for Māori than New Zealanders from European backgrounds. ${ }^{22}$ Caring for those most vulnerable and tackling inequities remains a challenge throughout high-income, middle-income and low-income countries alike.

The following vignettes describe experiences from the People's Republic of China (box 3) and Singapore (box 4) in confronting the COVID-19 pandemic. These
Box 3 The People's Republic of China (P.R. China) topdown approach

- P.R. China adopted stringent top-down COVID-19 containment measures almost from the beginning and successfully contained the virus in Hubei province (where it began) within about 3 months. ${ }^{42}$ Emergency command mechanisms headed by party and government officials were established regionally and locally across the country, forming a top-down system with unified command, clear guidance and coordination between departments and provinces. Government directives on social distancing and shelter-in-place were rigorously implemented. Subsidised testing and treatment were made available promptly. P.R. China created an electronic infectious disease reporting system that collects individual case data through a unified digital reporting card ${ }^{43}$ which is then referred to the national Chinese Center for Disease Control and Prevention. Evidence indicated a delay in reporting of the early COVID-19 cases, alluding to an attempt at suppressing information, a lack of training of hospital staff and deficiencies in enforcing the reporting protocols - an important lesson for the country's public health systems. In a pandemic, there is a clear role and advantage for certain vertical responses and policies coordinated centrally. However, in building back better, stronger bottom-up empowerment will be crucial.

two countries were arguably much better prepared to prevent the worst effects and they both offer useful insights in terms of strengths and weaknesses in this regard.

\section{SYSTEMIC CHANGE TO FUTURE-PROOF SYSTEMS}

The COVID-19 pandemic has been enough of a shock to most countries to provoke consideration of a more joined-up, systems-wide change in health, economic and political systems. Understanding how change happens in

\section{Box 4 The case of Singapore-failure to implement care} strategies for migrant workers

Singapore's successful dengue control programme is hosted by the National Environmental Agency in accordance with the country's larger vision of a clean, green and sustainable environment for the health and well-being of its citizens. Key to this success is that dengue is recognised as an environmental disease. The country relies on a sophisticated information and data sharing system, which allows government, private and community structures to coordinate and collaborate among a multiplicity of ministries and non-governmental entities. Singapore's dengue control programme succeeded in reducing the dengue force of infection 10 -fold by the 1990s and has maintained it at low levels ever since. ${ }^{44}$ Despite these remarkable achievements in controlling an epidemic-prone disease, COVID-19 revealed the country's weaknesses in emergency preparedness and response. A large proportion of Singapore's COVID-19 cases were migrants who lived in the overcrowded dormitories that house more than 300000 of Singapore's roughly 1 million migrant workers, a highly vulnerable population group, most of whom are nationals of NTD endemic low- and middle-income countries. For this reason, COVID-19 presented a formidable challenge to a country that seemed to have all the necessary ingredients to effectively tackle the crisis. $^{45}$ 
complex adaptive systems requires systems thinking and acknowledgement that systems-wide change is not linear. Systems thinking provides a discipline and a language for stakeholders to better understand and respond to the dynamics of persistent global and local health challenges. ${ }^{23}$ It provides a conceptual approach and methods to envisage alternative futures, identify tipping points for change, and open new ways of analysing, organising and communicating. ${ }^{24}$ Rather than simply reacting to events, as has been the primary approach to this pandemic, systems thinking emphasises anticipating patterns of system behaviour based on a deeper understanding of underlying system structures and drivers. As there is no single solution for the multiple problems humanity faces, concerted efforts are needed to take into account the interplay across systems. Here we provide five arguments for combining climate, economic, health and sociopolitical systems into a 'one health', integrated approach.

\section{Urgently address the climate emergency}

A recent report from the United Nations on the state of nature $^{25}$ found that the world has failed to meet a single target to stem the destruction of wildlife and life-sustaining ecosystems in the last decade. The COVID-19 pandemic has served as a reminder of the close inter-connectedness among human, animal and environmental health, and the urgent need to address them holistically. The anthropogenic influences on the emergence of zoonotic diseases are clear and we must recognise how the health of the planet directly impacts human health. ${ }^{26}$ Examples of NTDs expansion into previously non-endemic areas, attributable in all likelihood to climate change, include dengue and leishmaniasis. ${ }^{27}$

The disproportionate impact of climate change on marginalised populations has been well documented. Mirroring the same 'vicious cycle' as COVID-19 and NTDs, initial inequalities mean vulnerable groups are more impacted due to the adverse effects of climate change, resulting in greater subsequent inequality. Addressing the climate emergency is part and parcel of addressing health inequities.

\section{Alternative economic models need to shift the focus away from growth towards well-being}

Economic growth has helped lift people out of poverty but beyond a certain point, it becomes unsustainable. Perpetual growth, which relies on the exploitation of finite resources inevitably leads to conflict and environmental catastrophe. Bhutan recognised this in 1972 when the country's king declared, 'Gross National Happiness is more important than Gross Domestic Product'. The concept implies that sustainable development should take a holistic approach to notions of progress and give equal importance to non-economic aspects of well-being. ${ }^{28}$ Similarly, in 2019, New Zealand shifted its economic goal from increasing gross domestic product to improving the welfare of New Zealand's citizens. ${ }^{29}$
COVID-19 has spurred interest in alternate economic models and triggered discussions on issues such as the need to stop austerity, forgiving debts and progressive taxation to fund a rehaul of public services.

\section{Address the social determinants of health, reduce inequities and tackle systemic racism}

Good quality healthcare is a fundamental human right and a major determinant of health. Access, affordability and acceptability of health are all socially and politically determined. Yet, many of the determinants of health lie outside the healthcare system, including education, housing, work and income. ${ }^{30}$ Addressing the social determinants of health is key to the prevention and control of NTDs, and at the same time, NTDs lead to a deterioration in the social determinants of health.

Progressive concepts that before COVID-19 may have been considered unfeasible or even radical are now being considered in mainstream circles-these include a universal basic income and universal public services. The latter is increasingly considered as one of the most effective tools in reducing inequities. ${ }^{31}$

The disproportionate impact of the pandemic on ethnic minority groups is now widely recognised as having highlighted structural racism (how societies foster discrimination through mutually reinforcing inequitable systems). ${ }^{32}$

\section{Strengthen community-oriented primary healthcare}

The recent Declaration of Astana marked a commitment to strengthening primary healthcare as the basis for resilient health systems and the most effective way to achieve universal coverage. There is an increasing call to turn this declaration into action. ${ }^{33}$

Community-oriented primary care stimulates people's capabilities to maintain health and live in the community with complex chronic conditions. This is relevant not only for managing COVID-19 and its long-term effects already unfolding but also for managing NTDs and their residual disability burden in the community. Box 5 describes Ghana's approach to COVID-19, with its focus on community.

\section{Integrate at all levels}

The fragmentation of current health systems significantly impairs our ability to respond effectively in times of crises. Fragmentation leads to duplication, inefficiencies, poorer outcomes and an unsatisfactory experience of care. There is growing evidence that integration of services in the health system and across sectors increases the resilience of systems. ${ }^{34}$ The International Foundation for Integrated Care recently updated its pillars of integration $^{35}$ which provide a useful starting point for investing in health in all policies and government approaches. The pillars include (i) shared values and vision; (ii) local context and population health; (iii) people at the centre and as partners; (iv) new alliances for resilient communities; (v) workforce capacity and capability; (vi) system 
Box 5 Ghana's focus on the community in its approach to COVID-19 $19^{46}$

- As COVID-19 rapidly began spreading across borders, many feared it would result in enormous mortality in Africa, overwhelming the continent's already stretched healthcare systems. On the contrary, African countries appear to be mostly coping and, as such, are a valuable source of insights. The fight against COVID-19 in Ghana was centrally led by the presidency that brought together multiple sectors to tackle the problem, not only as a health issue but also as a developmental one. A large number of community health workers were rapidly deployed to follow-up contact tracing. In the spirit of ensuring Universal Health Coverage, all COVID-19 cases were treated free of charge. In support of the COVID-19 prevention and containment measures, the government agreed to absorb water bills and introduced rebates on electricity bills of all Ghanaians. A coronavirus alleviation programme was set up to support households, including the provision of a warm meal a day for vulnerable populations, tax relief, insurance coverage, free bus rides for frontline health workers, and soft loans for small- and medium-scale businesses. The sustainability of these social protection measures remains to be evaluated. Ghana has demonstrated the importance of leadership combined with the ability to bring the different components of the health and social systems together towards a common aim, and crucially, further orienting health systems towards the community.

wide governance and leadership; (vii) digital solutions; (viii) aligned payment systems; and (ix) transparency of progress, results and impact.

\section{NTDS AS A BAROMETER FOR BUILDING BACK BETTER}

Now that COVID-19 is here, there will be no return to pre-pandemic normal. We must learn to live in a COVID-endemic world that is still vulnerable to further pandemics. Indeed, the current COVID-19 pandemic is starting to be recognised as a syndemic ${ }^{36}$ due to the synergy of the epidemic with our social determinants of health.

The opportunity for change is truly now or never. Economic development agendas are proving to be highly dynamic and major financial commitments are being made by some of the leading financial institutions and international organisations. Opportunities to access some of these resources are now becoming available as part of the ongoing and future economic development agendas and public health priorities driven by the COVID-19 pandemic. ${ }^{8}$

Where do NTDs fit in this agenda? The COVID-19 pandemic has hit hardest the neglected and marginalised populations. Assuming that the world moves forward with the required reforms, success could be measured in how well the most neglected populations benefit. Several of the measures taken to prevent and manage NTDs (eg, water, sanitation, hygiene and health education) are the same measures currently used to prevent the spread of COVID-19. However, success in reducing COVID-19 without a concomitant reduction in NTDs will indicate that the proposed system-wide and sustainable changes have been insufficient. NTDs also offer valuable insights when it comes to deploying prevention and response measures, developing effective communication strategies and designing future policies, systems and services. ${ }^{37}$

Tackling NTDs is a moral and humanistic imperative to which the world committed long ago. It is clear that for NTDs to attain their ultimate elimination goals where feasible, or successful control where elimination is not realistic, a social justice and system-wide approach is needed in every endemic country, the very same that will be required to face the challenge of the current COVID-19 and any future pandemic. Failure to control or eliminate NTDs will be a direct reflection of our inability to respond to the needs of the most disadvantaged and neglected populations. NTDs are thus the barometer we need to monitor our progress towards building back better and ensuring we are prepared for future disease outbreaks and any other major global challenge.

\section{Author affiliations}

${ }^{1}$ International Foundation for Integrated Care, Oxford, UK

${ }^{2}$ Retired, World Health Organization, Manila, Philippines

${ }^{3}$ Laboratory of Parasitology, Central-West Campus, Federal University of São João del Rei, Divinopolis, Brazil

${ }^{4}$ Centre for Health Policy and Implementation Research, University of Health and Allied Sciences, Ho, Ghana

${ }^{5}$ Swiss Tropical and Public Health Institute, Basel, Switzerland

${ }^{6}$ University of Basel, Basel, Switzerland

${ }^{7}$ National Institute of Parasitic Diseases at the Chinese Center for Disease Control and Prevention, Shanghai, China

${ }^{8}$ School of Global Health, Chinese Center for Tropical Diseases Research, Shanghai Jiao Tong University School of Medicine, Shanghai, China

Acknowledgements We are grateful to Professor Carol Vlassoff for reviewing the draft manuscript and providing valuable insights.

Contributors The concept of the paper was developed by Don de Savigny. The lead writer was Nieves Ehrenberg. The other coauthors contributed equally to the content development.

Funding The authors have not declared a specific grant for this research from any funding agency in the public, commercial or not-for-profit sectors.

Competing interests None declared.

Patient consent for publication Not required.

Provenance and peer review Not commissioned; externally peer reviewed.

Data availability statement There are no data in this work.

Open access This is an open access article distributed in accordance with the Creative Commons Attribution Non Commercial (CC BY-NC 4.0) license, which permits others to distribute, remix, adapt, build upon this work non-commercially, and license their derivative works on different terms, provided the original work is properly cited, appropriate credit is given, any changes made indicated, and the use is non-commercial. See: http://creativecommons.org/licenses/by-nc/4.0/.

ORCID iD

Nieves Ehrenberg http://orcid.org/0000-0002-0760-9711

\section{REFERENCES}

1 Biddle L, Wahedi K, Bozorgmehr K. Health system resilience: a literature review of empirical research. Health Policy Plan 2020;35:1084-109.

2 Ahmed F, Ahmed N, Pissarides C, et al. Why inequality could spread COVID-19. Lancet Public Health 2020;5:e240. 
3 Ramos G, Hynes W, Müller J-M, et al. Systemic Thinking for Policy Making - the Potential of Systems Analysis for Addressing Global Policy Challenges in the 21st Century 2019.

4 Bill \& Melinda Gates Foundation. 2020 Goalkeepers Report. [Internet], 2020. Available: https://www.gatesfoundation.org/ goalkeepers/downloads/2020-report/report_en.pdf [Accessed cited 2020 Oct 22].

5 Milner A, Jumbe S. Using the right words to address racial disparities in COVID-19. Lancet Public Health 2020;5:e419-20.

6 Hanefeld J, Mayhew S, Legido-Quigley $\mathrm{H}$, et al. Towards an understanding of resilience: responding to health systems shocks. Health Policy Plan 2018;33:355-67.

7 Kruk ME, Myers M, Varpilah ST, et al. What is a resilient health system? Lessons from Ebola. Lancet 2015;385:1910-2.

8 Ehrenberg JP, Utzinger J, Fontes G, et al. Efforts to mitigate the economic impact of the COVID-19 pandemic: potential entry points for neglected tropical diseases. Infect Dis Poverty 2021;10:2.

9 World Health Organization. Neglected tropical diseases. Available: https://www.who.int/neglected_diseases/diseases/en/ [Accessed 10 Oct 2020].

10 Utzinger J, Becker SL, Knopp S, et al. Neglected tropical diseases: diagnosis, clinical management, treatment and control. Swiss Med Wkly 2012;142:19-22.

11 2020: a crucial year for neglected tropical diseases. Lancet 2019;394:2126.

12 Ehrenberg JP, Ault SK. Neglected diseases of neglected populations: thinking to reshape the determinants of health in Latin America and the Caribbean. BMC Public Health 2005;5:119.

13 Institute of Medicine (US) Forum on Microbial Threats. The causes and impacts of neglected tropical and zoonotic diseases: opportunities for integrated intervention strategies. Washington (DC: National Academies Press (US), 2011. https://www.ncbi.nlm.nih.gov/ books/NBK62507/

14 Hotez PJ. Ten failings in global neglected tropical diseases control. PLoS Negl Trop Dis 2017;11:4-7.

15 World Health Organization. Ending the neglect to attain the sustainable development goals: a road map for neglected tropical diseases 2021-2030, 2020. Available: https://www.who.int/ neglected_diseases/resources/who-ucn-ntd-2020.01/en/ [Accessed 25 Mar 2021].

16 Health Policy Watch. Neglected Tropical Disease Programmes on Pause due to COVID-19. [Internet]. Available: https://healthpolicywatch.news/neglected-tropical-disease-programmes-on-pause-dueto-covid-19/ [Accessed 10 Oct 2020].

17 World Health Organization (27 July 2020) Considerations for implementing mass treatment, active case-finding and populationbased surveys for neglected tropical diseases in the context of the COVID-19 pandemic: interim guidance.

18 Ministerio da Economia. Brazil's Policy Responses to COVID-19, 2020. Available: https://www.gov.br/economia/pt-br/centrais-deconteudo/publicacoes/publicacoes-em-outros-idiomas/covid-19/ brazil2019s-policy-responses-to-covid-19 [Accessed 10 Oct 2020].

19 Gobierno de Mexico. Todo sobre Covid, 2020. Available: https:// coronavirus.gob.mx/ [Accessed 10 Oct 2020].

20 Department of Health and Human Services USA. U.S. Government COVID-19 Response Plan. Available: https://int. nyt.com/data/documenthelper/6819-covid-19-response-plan/ d367f758bec47cad361f/optimized/full.pdf [Accessed 10 Oct 2020].

21 Cabinet Office UK. Our plan to rebuild: The UK Government's COVID-19 recovery strategy. Available: https://www.gov.uk/ government/publications/our-plan-to-rebuild-the-uk-governmentscovid-19-recovery-strategy/our-plan-to-rebuild-the-uk-governmentscovid-19-recovery-strategy [Accessed 10 Oct 2020].

22 Steyn N, Binny RN, Hannah K, et al. Estimated inequities in COVID-19 infection fatality rates by ethnicity for Aotearoa New Zealand. N Z Med J 2020;133:28-39.

23 de Savigny D, Adam T. Systems thinking for health systems strengthening. Geneva: WHO Alliance for Health Policy and Systems Research, 2009

24 Glenn J, Kamara K, Umar ZA, et al. Applied systems thinking: a viable approach to identify leverage points for accelerating progress towards ending neglected tropical diseases. Health Res Policy Syst 2020;18:56.
25 Secretariat of the Convention on Biological Diversity. Global biodiversity outlook 5. Montreal, 2020. Available: https://www.cbd. int/gbo5 [Accessed 10 Oct 2020].

26 Dobson AP, Pimm SL, Hannah L, et al. Ecology and economics for pandemic prevention (supplementary material). Science 2020;369:379-81.

27 Salomón OD, Quintana MG, Mastrángelo AV, et al. Leishmaniasis and climate change-case study: Argentina. J Trop Med 2012;2012:1-11.

28 Centre for Bhutan Studies \& GNH. A Short Guide to GNH Index [Internet]. Available: http://www.grossnationalhappiness.com/ashort-guide-to-gnh-index/ [Accessed 10 Oct 2020].

29 New Zealand Treasury. The Wellbeing Budget. Wellington. [Internet]. Available: https://www.treasury.govt.nz/sites/default/files/2019-05/ b19-wellbeing-budget.pdf [Accessed 10 Oct 2020].

30 Commission on Social Determinants of Health. Closing the gap in a generation - Health equity through action on the social determinants of health. Final Report of the Commission on Social Determinants of Health. Geneva, 2008.

31 Coote A, Kasliwal P, Percy A. Universal basic services: theory and practice 2019.

32 Paradies Y, Ben J, Denson N, et al. Racism as a determinant of health: a systematic review and meta-analysis. PLoS One 2015;10:1-48.

33 World Health Organization. Stronger collaboration, better health: global action plan for healthy lives and well-being for all: strengthening collaboration among multilateral organizations to accelerate country progress on the health-related sustainable development goals. Geneva: World Health Organization, 2019.

34 Kruk ME, Ling EJ, Bitton A, et al. Building resilient health systems: a proposal for a resilience index. BMJ 2017;357:j2323.

35 Lewis L, Ehrenberg N. Realising the true value of integrated care: beyond COVID-19. Oxford: International Foundation for Integrated Care, 2020. https://integratedcarefoundation.org/covid-19knowledge/realising-the-true-value-of-integrated-care-beyondcovid -19 ?mc cid $=$ d14b279384\&mc eid $=c 7$ eb609b15

36 Horton R. Offline: COVID-19 is not a pandemic. Lancet 2020;396:874.

37 Ehrenberg JP, Zhou X-N, Fontes G, et al. Strategies supporting the prevention and control of neglected tropical diseases during and beyond the COVID-19 pandemic. Infect Dis Poverty 2020;9:86.

38 Gomes FFC, Cherchiglia ML, Machado CD. Acesso aos procedimentos de média e alta complexidade no sistema único de saúde: Uma questão de judicialização. Cadernos de Saude Publica 2014;30:31-43.

39 Costa AM, Rizzotto MLF, de Vasconcelos Costa Lobato L. In the Covid-19 pandemic, Brazil sees the SUS. Saúde em Debate 2020;44:289-96.

40 Medilab S. Medlab Sistemas. Conheça os 9 maiores problemas de saúde pública no Brasil. [Internet]. Available: http://medilab.net.br/ 2019/01/29/9-maiores-problemas-de-saude-publica [Accessed 30 Sep 2020].

41 Gyapong JO, Owusu IO, da-Costa Vroom FB, et al. Elimination of lymphatic filariasis: current perspectives on mass drug administration. Res Rep Trop Med 2018;9:25-33.

42 Chen Z, Cao C, Yang G. Coordinated multi-sectoral efforts needed to address the COVID-19 pandemic: lessons from China and the United States. Glob Health Res Policy 2020;5:22.

43 Jiang Y, Dou X, Yan C, et al. Epidemiological characteristics and trends of notifiable infectious diseases in China from 1986 to 2016. J Glob Health 2020;10:020803.

$44 \mathrm{Sim}$ S, Ng LC, Lindsay SW, et al. A greener vision for vector control: the example of the Singapore dengue control programme. PLoS Negl Trop Dis 2020;14:1-20.

45 National Public Radio. Singapore was a shining star in COVID-19 control - until it wasn't. [Internet]. Available: https://www.npr.org/ sections/goatsandsoda/2020/05/03/849135036/singapore-wasa-shining-star-in-covid-control-until-it-wasnt?t=1602237113315 [Accessed 10 Oct 2020].

46 DeloitteApril. Economic impact of the Covid-19 pandemic on the economy of Ghana; 2020. https://www2.deloitte.com/content/dam/ Deloitte/gh/Documents/about-deloitte/gh-economic-Impact-ofthe-Covid-19-Pandemic-on-the-Economy-of-Ghana_06042020.pdf [Accessed 25 Mar 2021]. 